\title{
Thermal and Optical Properties of Epoxy/Siloxane Hybrimer Based on Sol-Gel-Derived Phenyl-Silloxane
}

\author{
Kuo-Hui Wu' ${ }^{1}$, Ken-Fa Cheng1, Cheng-Chien Yang'2, Chung-Pao Wang ${ }^{3}$, Chi-I Liu ${ }^{3}$ \\ ${ }^{1}$ Department of Chemical and Materials Engineering, Chung Cheng Institute of Technology, \\ National Defense University, Taoyuan, Taiwan \\ ${ }^{2}$ Chemical Systems Research Division, Chung Shan Institute of Science and Technology, Taoyuan, Taiwan \\ ${ }^{3}$ System Manufacturing Center, Chung Shan Institute of Science and Technology, Shanshia, Taiwan \\ Email: khwu@ndu.edu.tw
}

Received 25 March 2015; accepted 30 May 2015; published 2 June 2015

Copyright (C) 2015 by authors and Scientific Research Publishing Inc.

This work is licensed under the Creative Commons Attribution International License (CC BY).

http://creativecommons.org/licenses/by/4.0/

c) (i) Open Access

\section{Abstract}

A hybrimer based on epoxy resin and phenyl-siloxane was prepared by polymerization and a solgel condensation reaction in which Eporite-904 (807 g/eq) bisphenol-A-type epoxy resin, 3-isocyanatopropyltriethoxysilane (IPTES) and phenyltriethoxysilane (PTEOS) acted as precursors. The thermal and optical properties of the epoxy/siloxane hybrimer were studied. The thermogravimetric analysis (TGA) results implied that the hybrimer could increase the crosslink density and enhance the thermal properties. The optical properties were measured after thermal and UV aging. The refractive indexes of the epoxy/siloxane hybrimers were $1.66-1.70$, and the transmittances of the cured hybrimers were above $90 \%$ in the visible wavelength. After a $120^{\circ} \mathrm{C} / 24-\mathrm{h}$ thermal aging test, the decreases in the refractive index and transmittance were less than $5 \%$ and $20 \%$ respectively. The epoxy/siloxane hybrimers also showed low discoloration upon thermal aging at $120^{\circ} \mathrm{C}$ for $24 \mathrm{~h}$ under an air atmosphere.

\section{Keywords}

Epoxy, Siloxane, Encapsulating Material, Optical Properties

\section{Introduction}

White light-emitting diodes (LEDs) have received considerable attention in terms of lighting and displays as

\footnotetext{
"Corresponding author.
}

How to cite this paper: Wu, K.-H., Cheng, K.-F., Yang, C.-C., Wang, C.-P. and Liu, C.-I. (2015) Thermal and Optical Properties of Epoxy/Siloxane Hybrimer Based on Sol-Gel-Derived Phenyl-Siloxane. Open Journal of Composite Materials, 5, 49-59. 
they have the properties of an extended lifespan, driving at a low voltage, and high luminescence efficiency, and they are also heavy metal-free. Blue LED chips are generally used as light sources, incorporating yellow phosphor to produce white light. The blue light emitted by the blue LED chip is converted into white light when it passes through phosphors dispersed in the LED encapsulant. Among these components of white LEDs, the LED encapsulant plays an important role in obtaining high luminescence efficiency. It can be further improved by enhancing the refractive index of the encapsulant and modifying the structural design to inhibit total reflection and refraction of light [1]-[3].

Transparent epoxy resins are generally used as encapsulants in the blue LED assembly field [4]. However, there are two major disadvantages of using epoxy resins as LED encapsulants. One disadvantage is that cured epoxy resins are generally hard and brittle because of rigid cross-linked networks. The other disadvantage is that the degradation of epoxy resins under exposure to radiation and high temperature leads to chain scission and discoloration [5]-[7]. Silicone resins are excellent in terms of their thermal stability and UV resistance, but they are relatively weak with regards to their adhesion and mechanical strength [8] [9]. Therefore, there is a need to combine the advantages of epoxy resins, such as low cost, ease of processing, excellent mechanical properties, and good adhesion, with the advantages of silicone. Modification with silicone materials has been considered to be the most effective method to improve the toughness and thermal stability of transparent epoxy encapsulants [10]-[12].

Silicone can be formulated with different hardness properties: gel, elastic and hard types. Silicones used in optoelectronic products are generally of the elastic type in order to give flexibility to encapsulated wire bonds [13]. This characteristic provides the ability to absorb thermal stress during the soldering process and during application. The use of epoxy-silicone monomers in encapsulation is very attractive because epoxy-silicone offers the benefits of both silicone and epoxy resins. The siloxane bond is stable under heat and ultraviolet (UV) light, while epoxy resin has a high adhesive strength [14]. Epoxy-silicone hybrid materials based on sol-gel-derived oligosiloxane are candidate materials for encapsulation due to their excellent transparency [15]-[18]. In this polymer system, siloxane forms the matrix with epoxy and alkoxy functionality in the side chains. The condensation reaction of an aliphatic epoxy with a polysiloxane produces the novel chemistry of the epoxy-siloxane polymer. As the hybrid nature of the polymer indicates, two reactions take place. The amine group of the aminosilane cures the epoxy resin in a typical manner. At the same time, a competing polycondensation reaction occurs between the silicone alkoxy groups of the hardener and resin.

Hence, the combination of polysiloxane with epoxy resin has broader application possibilities. Yet, so far, there have been few reports of epoxy/siloxane hybrimers with thermal/UV resistance properties. In this study, we synthesized epoxy/siloxane hybrimers by sol-gel condensation and a polymerization reaction between bisphenol-A epoxy and phenyl-siloxane. The effects of different phenyl-siloxane concentrations (5 - $15 \mathrm{wt} \%$ ) on the thermal resistance, UV resistance and various cured polymer properties were studied in detail. The optical properties (refractive index, transmittance) before and after thermal/UV aging of the epoxy/siloxane hybrimers were examined to assess their feasibility as thermally-resistant and encapsulating materials.

\section{Experimental}

\subsection{Preparation of the Epoxy/Siloxane Hybrimers}

The epoxy/siloxane hybrimers were prepared as shown in Figure 1. The diglycidyl ether of bisphenol-A epoxy used in this work was supplied by Nan Ya Plastics Co., Ltd. Taiwan, with an epoxide equivalent weight of 807 g/eq (Eporite-904). An acid-catalyzed process, using 3-isocyanatopropyltriethoxysilane (IPTES, Acros, RG) and phenyltriethoxysilane (PTEOS, Aldrich, RG) as the precursors, was employed to prepare the phenyl-siloxane solution.

Eporite-904 resin (10 g) and tetrahydrofuran (THF; $10 \mathrm{ml}$ ) were stirred in a 250-ml three-neck round-bottle flask at $60^{\circ} \mathrm{C}$ to obtain the epoxy solution. Then, IPTES $(0.25,0.50$ and $0.75 \mathrm{~g})$ was added with tetrahydrofuran (THF, Tedia, AR) into the epoxy solution. The mixture was homogeneous, and was stirred at $60^{\circ} \mathrm{C}$ until the characteristic peak of the NCO group $\left(2270 \mathrm{~cm}^{-1}\right)$ in the FT-IR spectra disappeared (Figure 2). The reaction time was about $12 \mathrm{~h}$. NCO conversion during the synthesis has been calculated from the peak areas at $2270 \mathrm{~cm}^{-1}$, which was fitted using a Gaussian function. The conversion ratios of the NCO group were larger than 95\%. Quantitative PTEOS (molar ratio 1:1 with respect to IPTES) was placed in a beaker with $0.05 \mathrm{M} \mathrm{HNO}_{3}$ and deionized water by a simple sol-gel condensation reaction. The resulting solution was added to the above- 

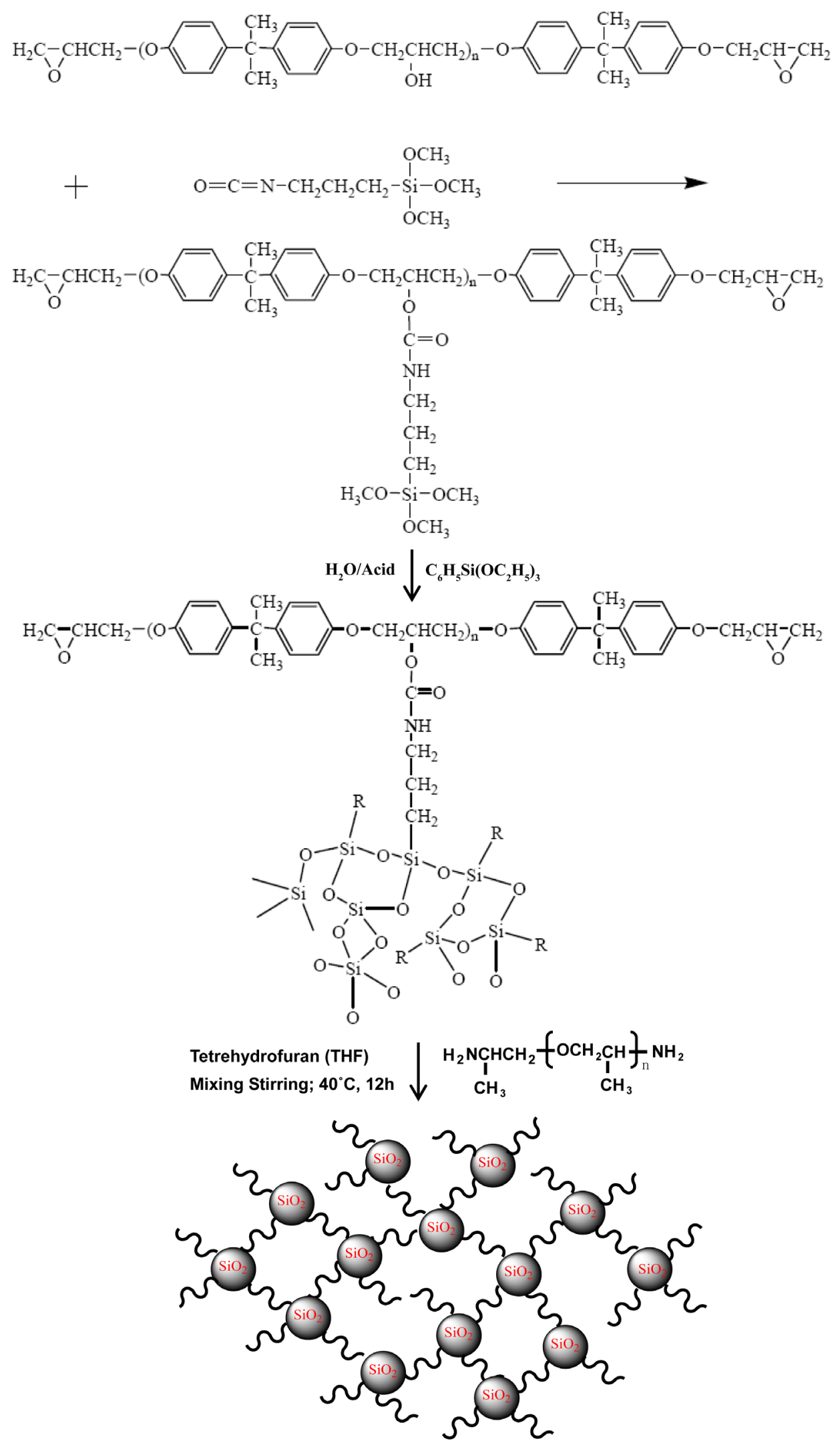

Figure 1. Experimental procedure for the synthesis of epoxy/siloxane hybrimer. 


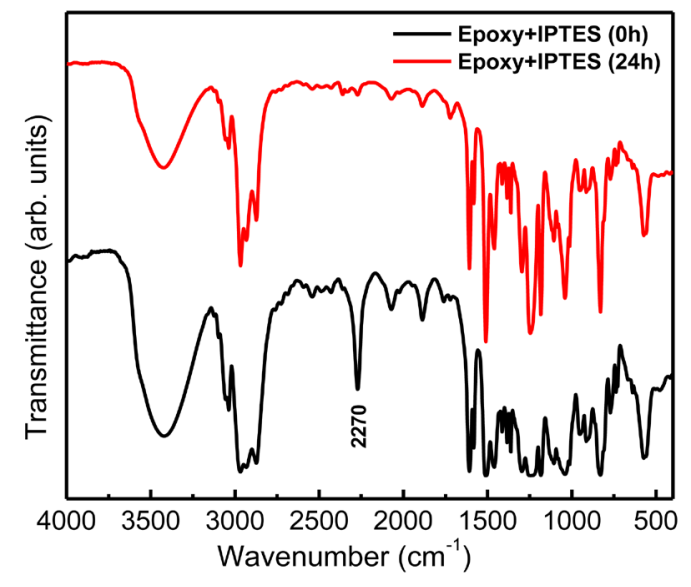

Figure 2. FTIR spectra of epoxy and IPTES before/ after reaction for $24 \mathrm{~h}$.

described sol solution, and stirring was continued under an inert atmosphere at room temperature for another $24 \mathrm{~h}$.

The various epoxy/siloxane hybrimers were prepared from epoxy and phenyl-siloxane (IPTEOS + PTEOS) with different ratios of phenyl-siloxane to epoxy (5, 10 and $15 \mathrm{wt} \%)$. Eporite-904 epoxy reacted with 5/10/15 wt\% phenyl-siloxane is abbreviated as epoxy/siloxane hybrimer-5, epoxy/siloxane hybrimer-10 and epoxy/siloxane hybrimer-15, respectively. Then, B210 diamine (Acros, RG) was used as the curing agent for the modified epoxy resin. The phenyl-siloxane modified epoxy underwent removal of THF in a vacuum oven at room temperature for $1 \mathrm{~h}$ and was then cast onto a polytetrafluoroethylene plate in order to gel at room temperature for $24 \mathrm{~h}$. The samples were placed in a drying oven at $70^{\circ} \mathrm{C}$ for $24 \mathrm{~h}$ to obtain the clear epoxy/siloxane hybrimers. Additionally, the epoxy/siloxane hybrimers were thermally aged at $100 / 120 / 150^{\circ} \mathrm{C}$ for $24 \mathrm{~h}$ and $\mathrm{UV}$ aged at 365 nm for $8 / 16 / 24 \mathrm{~h}$.

\subsection{Experimental Techniques}

The epoxy/siloxane hybrimers were confirmed by Fourier transform infrared (FTIR) spectral analysis (Tensor 27) of samples prepared by the $\mathrm{KBr}$ pellet technique. The morphologies of the samples were observed using a scanning electron microscope (SEM, Hitachi S-800) equipped with an energy-dispersive X-ray (EDX) microanalysis system. Atomic force microscope (AFM) experiments were carried out in both height and phase contrast modes using a VEECO DI3100 scanning force microscope in a taping mode. A Perkin-Elmer thermal gravimetric analyzer (TGA-7) was used to investigate the thermal stabilities of the samples. The samples ( $\sim 5 \mathrm{mg})$ were heated in a $\mathrm{N}_{2} /$ air atmosphere from ambient temperature to $700^{\circ} \mathrm{C}$ at a heating rate of $10^{\circ} \mathrm{C} / \mathrm{min}$, and the gas flow rate was kept at $50 \mathrm{~mL} / \mathrm{min}$. Light transmittance measurements of the samples before and after aging were performed with a UV-Vis spectrophotometer (UV3101PC, Shimadzu) in a wavelength range of $400-800$ $\mathrm{nm}$. The refractive indexes of the samples were obtained using a He-Ne Laser $(10 \mathrm{~mW})$ with a prism coupler at a wavelength of $632.8 \mathrm{~nm}$.

\section{Results and Discussion}

\subsection{Molecular and Structural Characterization}

FTIR was used to examine the degree of curing after phenyl-siloxane was introduced into the systems. Shown in Figure 3 are the FTIR spectra of epoxy and the epoxy/siloxane hybrimers. The characteristic absorption bands of epoxy are at $3200-3700 \mathrm{~cm}^{-1}$ (O-H stretching), 3057/3036 $\mathrm{cm}^{-1}$ (aromatic C-H stretching), 2968/2928/2870 $\mathrm{cm}^{-1}$ (C-H stretching), 1607/1580/1516 $\mathrm{cm}^{-1}$ (aromatic C=C and C-C stretching), $1450 \mathrm{~cm}^{-1}$ (- $\mathrm{CH}_{2}$ - bridge deformation), $1300 \mathrm{~cm}^{-1}$ (epoxy O-H in-plane deformation), 1260 and $1060 \mathrm{~cm}^{-1}$ (benzene ring C-O-C stretching). The characteristic absorption bands of phenyl-siloxane are at $3100-3700 \mathrm{~cm}^{-1}$ (Si-OH and N-H stretching), $1734 \mathrm{~cm}^{-1}$ (C=O stretching), $1000-1100 / 890 \mathrm{~cm}^{-1}$ (Si-O-Si stretching and bending) and $950 \mathrm{~cm}^{-1}$ (Si-OH stretching). 


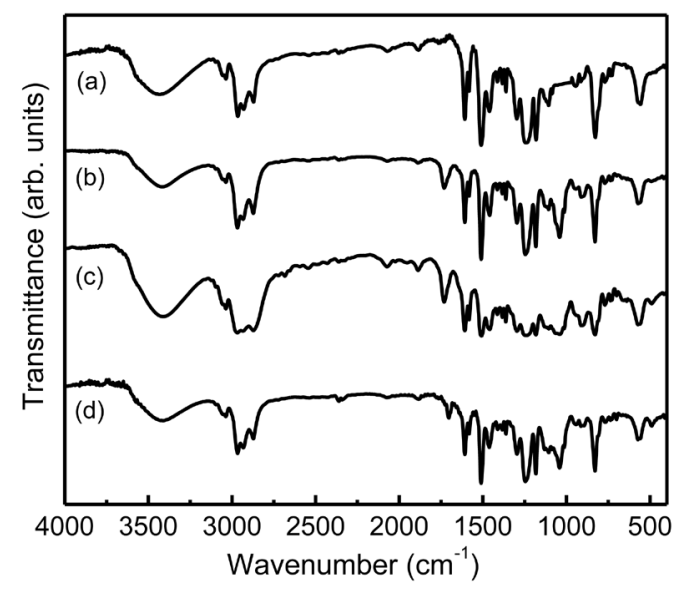

Figure 3. FTIR spectra of (a) epoxy, (b) epoxy/siloxane hybrimer-5, (c) epoxy/siloxane hybrimer-10, (d) epoxy/siloxane hybrimer-15.

The compatibility of the organic polymer and phenyl-siloxane greatly affects the thermal and optical properties. The morphology of the fractured surfaces was observed by SEM, and the EDX mapping technique was used to elucidate the distribution of silica and the separation of the microphase in the hybrimer matrix. Figure 4 presents SEM, EDX and Si mapping photographs of the morphologies of epoxy and the epoxy/siloxane hybrimers. As can be seen from the SEM photographs, the cured neat epoxy exhibited a very dense and smooth surface. As the content of phenyl-siloxane in the network increased, the surface became rougher and a heterogeneous morphology was exhibited in the matrix. The SEM photographs revealed that silica particles of $100-300$ $\mathrm{nm}$ in size were dispersed in the epoxy matrix. Moreover, EDX of these hybrimers indicated the presence of a significant amount of silicon in the matrix, indicating a phenyl-siloxane presence in these hybrimers. From the SEM and Si mapping photographs, the phenyl-siloxane was found to be uniformly dispersed throughout the epoxy matrix. This result revealed that the hybrimers exhibited good miscibility between the organic and inorganic phases.

2D and 3D AFM images of the surface obtained for the epoxy and epoxy/siloxane hybrimer samples are shown in Figure 5. In the 3D image, the parts of the wave trough corresponding to the soft-segment and the parts of the wave crest corresponding to the hard-segment can be observed, which indicated that there was a micro-phase separation in the molecules. It was observed that addition of phenyl-siloxane to epoxy leads to an increase in viscosity; however, the samples show a similar surface roughness and soft- and hard-segment distribution. This result revealed that the hybrimers exhibited good compatibility between the epoxy and phenyl-siloxane phases.

\subsection{Thermal Stability of the Epoxy/Siloxane Hybrimers}

Application of epoxy/siloxane hybrimers requires investigation of thermal properties such as thermal stability or structural change during thermal curing. Thus, the thermal stabilities of the epoxy/siloxane hybrimers were studied by TGA/DTG. The weight loss as well as various pyrolysis steps up to $700^{\circ} \mathrm{C}$ in $\mathrm{N}_{2}$ and air are shown in Figure 6(a) and Figure 6(b). It was seen that all the TGA curves displayed similar degradation profiles, implying a similar mechanism. Furthermore, the weight loss and main pyrolysis steps of the hybrimers depended upon the phenyl-siloxane content. In case of Figure 6(a), the weight loss of the epoxy/siloxane hybrimer observed below $180^{\circ} \mathrm{C}$ was due to the physical adsorption and hydrogen bonding of water in the samples and the major mass loss observed at $340^{\circ} \mathrm{C}-500^{\circ} \mathrm{C}$. However, the water content was $10 \mathrm{wt} \%$ or less, which was detrimental to the LED chip. Therefore, after the cure reaction the samples were subsequently placed in an oven at $100^{\circ} \mathrm{C}$ for $24 \mathrm{~h}$ to decrease the water content. In addition, the incorporation of phenyl-siloxane into epoxy resulted in a significant improvement in thermal stability, with a retarded mass loss rate and an enhanced char yield. This effect was increasingly pronounced with increasing concentrations of covalently-bound phenyl-siloxane in the epoxy system. 


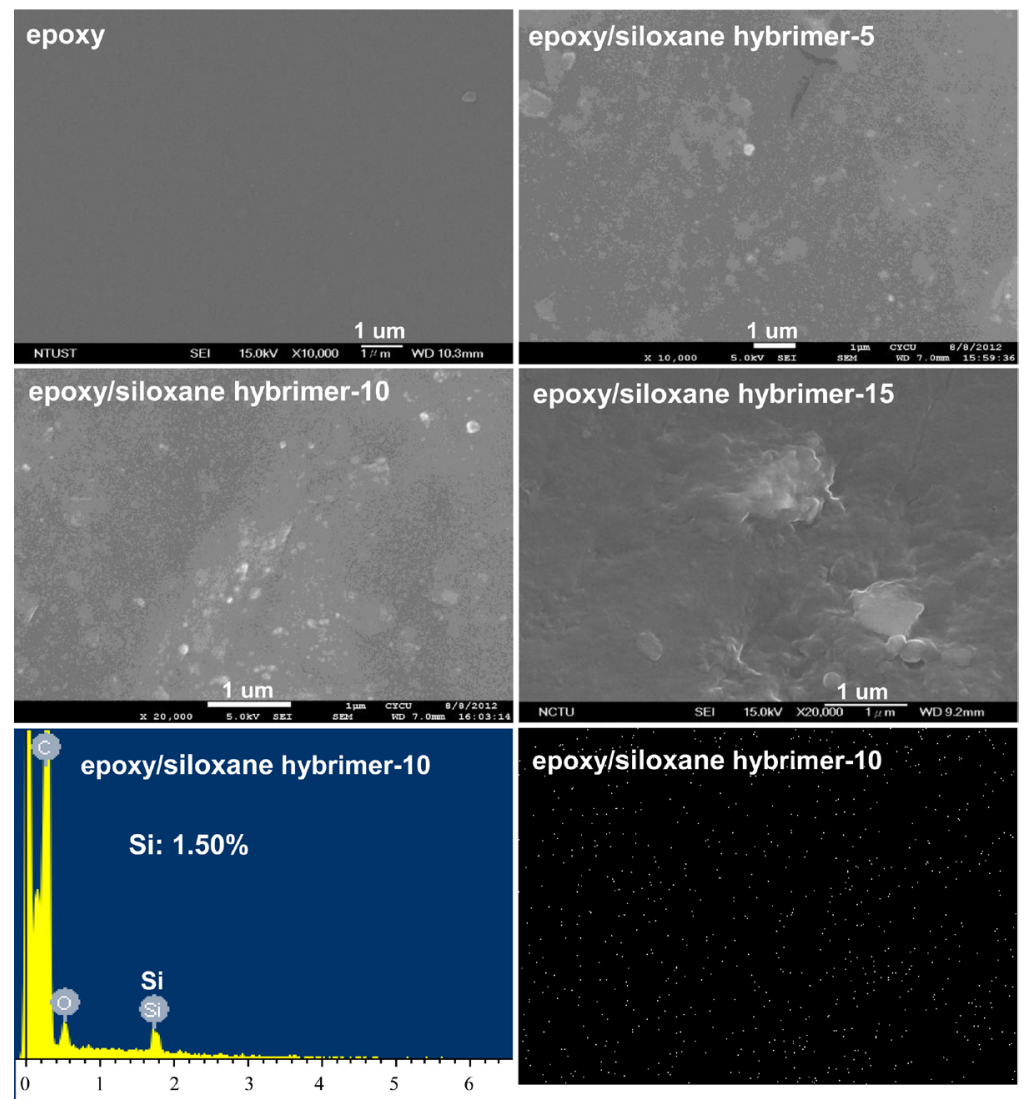

Figure 4. SEM, EDX and Si-mapping photographs of the series of epoxy/siloxane hybrimer.
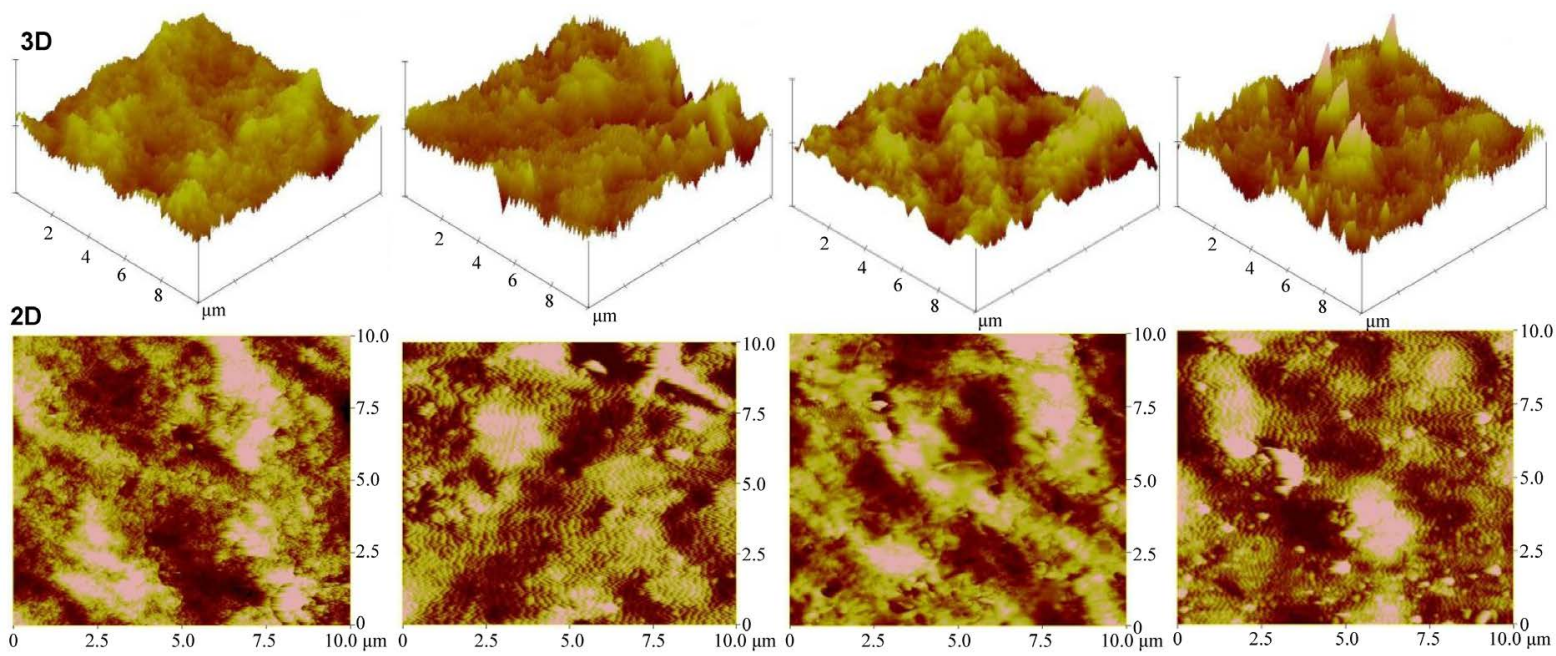

Mean roughness $16.59 \mathrm{~nm}$

Mean roughness $16.75 \mathrm{~nm}$

(b)
Mean roughness $16.78 \mathrm{~nm}$

(c)
Mean roughness $16.82 \mathrm{~nm}$

(d)

Figure 5. AFM (3D/2D) spectra of (a) epoxy, (b) epoxy/siloxane hybrimer-5, (c) epoxy/siloxane hybrimer-10, (d) epoxy/siloxane hybrimer- 15 .

The TGA/DTG curves, recorded in air, of the epoxy and the epoxy/siloxane hybrimers are shown in Figure 6(b). The major mass loss of epoxy can be attributed to the breakdown of the hydrocarbon soft segment phase 

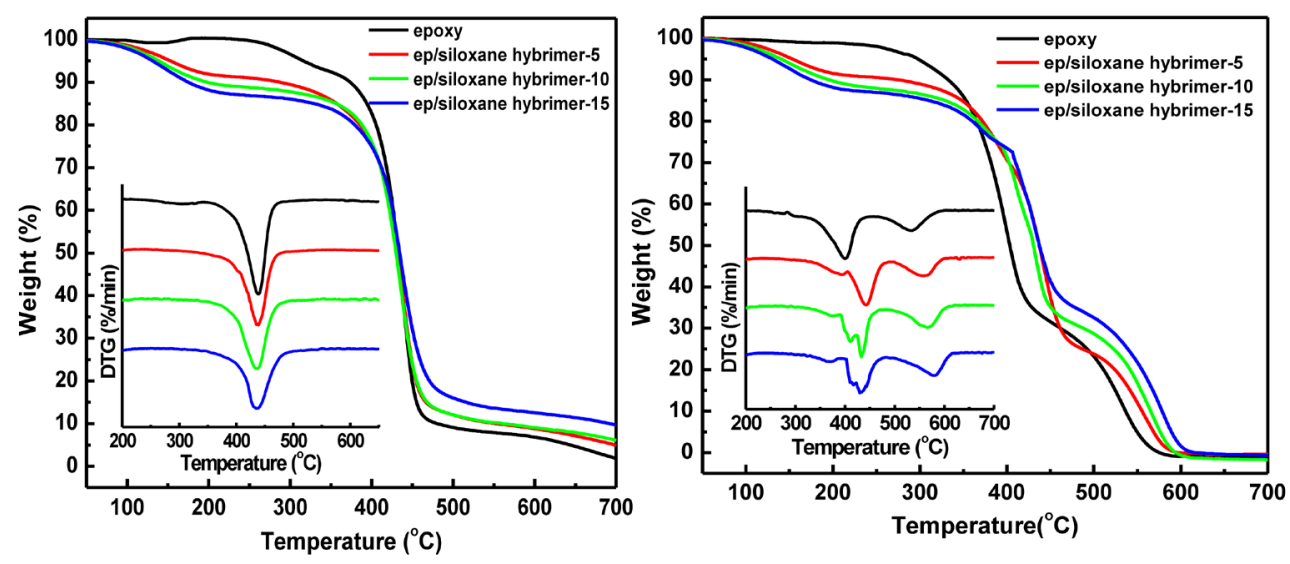

Figure 6. TGA spectra of the epoxy and epoxy/siloxane hybrimerin (a) $\mathrm{N}_{2}$ and (b) air.

$\left(300^{\circ} \mathrm{C}-450^{\circ} \mathrm{C}\right)$ and the hard segment phase $\left(450^{\circ} \mathrm{C}-600^{\circ} \mathrm{C}\right)$. It was observed that the thermo-oxidative decomposition temperatures were enhanced for the hybrimers, which increased with increasing phenyl-siloxane content. This relatively high thermo-oxidative stability can be explained based on the presence of a -Si-O-Siinorganic network, because the bond dissociation energy of Si-O is higher than that of C-C and C-O. The epoxy/siloxane hybrimers contained a silicone element. However, all the TGA curves of the samples in air showed that there was no residual left at $700^{\circ} \mathrm{C}$. The result may be due to errors in sampling when the epoxyrich samples were taken.

\subsection{Optical and Thermal Resistance Properties of the Epoxy/Siloxane Hybrimers}

Most optical polymers suffer a yellowing phenomenon under UV-radiation or thermal aging. Typically, this phenomenon is due to the aromatic group or free radicals in the optical polymer. The degree of yellowing can be judged by the loss of transmittance. The main reason for the decrease in light output in a LED package is the yellowing of the encapsulating materials. Therefore, measuring the loss of transmittance in an encapsulant of epoxy is a method by which we are able to understand the LED reliability. Figure 7 shows photographs of the samples before and after thermal aging at $100 / 120 / 150^{\circ} \mathrm{C}$ in air for $24 \mathrm{~h}$. Discoloration was barely distinguishable by the naked eye for all the samples at an aging temperature of $100^{\circ} \mathrm{C}-120^{\circ} \mathrm{C}$. Yet, the samples showed little yellowing upon thermal aging at $150^{\circ} \mathrm{C}$ under air. The result may be due to phenyl oxidation leading to chain scission and discoloration.

Figure 8 and Table 1 present optical transmission spectra and changes in transmittance (\%) at 460 and 550 $\mathrm{nm}$ for samples aged at $100^{\circ} \mathrm{C}, 120^{\circ} \mathrm{C}$, and $150^{\circ} \mathrm{C}$ for $24 \mathrm{~h}$ under an air atmosphere in comparison with those of the initial sample before aging. The transmittances of epoxy and the epoxy/siloxane hybrimers at 460 and 550 $\mathrm{nm}$ before thermal aging were larger than $90 \%$. After thermal aging at $100 / 120 / 150^{\circ} \mathrm{C}$, the transmittances of epoxy and epoxy/siloxane hybrimer-15 at $460 \mathrm{~nm}$ were $79 / 68 / 68 \%$ and $85 / 80 / 57 \%$, respectively. As shown in Table 1, the transmittances of the epoxy/siloxane hybrimer at 460 and $550 \mathrm{~nm}$ were higher than that of epoxy, despite thermal aging at $100^{\circ} \mathrm{C}-120^{\circ} \mathrm{C}$ under air. After $150^{\circ} \mathrm{C}$ thermal aging, the epoxy/siloxane hybrimers suffered more transmittance loss at $460 \mathrm{~nm}$ than epoxy due to the presence of the aromatic functional group. In general, phenyl-containing materials are susceptible to yellowing, because phenyl radicals are cleaved from backbone chains by thermal aging. Hence, the epoxy/siloxane hybrimers can withstand thermal aging up to $120^{\circ} \mathrm{C}$ under air.

Figure 9 and Table 2 present optical transmission spectra and changes in transmittance (\%) at 460 and 550 $\mathrm{nm}$ for samples after UV aging at 8, 16, and $24 \mathrm{~h}$ under an air atmosphere. After UV aging for 8/16/24 h, the transmittances of epoxy and epoxy/siloxane hybrimer- 15 at $460 \mathrm{~nm}$ were $79 / 73 / 69 \%$ and $87 / 83 / 74 \%$, respectively. As shown in Table 2, the transmittances of the epoxy/siloxane hybrimers at 460 and $550 \mathrm{~nm}$ were higher than that of epoxy, despite UV aging for $24 \mathrm{~h}$ under air. The epoxy/siloxane hybrimers were evidently superior to epoxy in terms of UV resistance. Moreover, the addition of a small amount of phenyl-siloxane performed effectively to improve the UV stability. This might be due to the high bonding energy of the siloxane structure and could enhance the UV resistance of the epoxy system. 


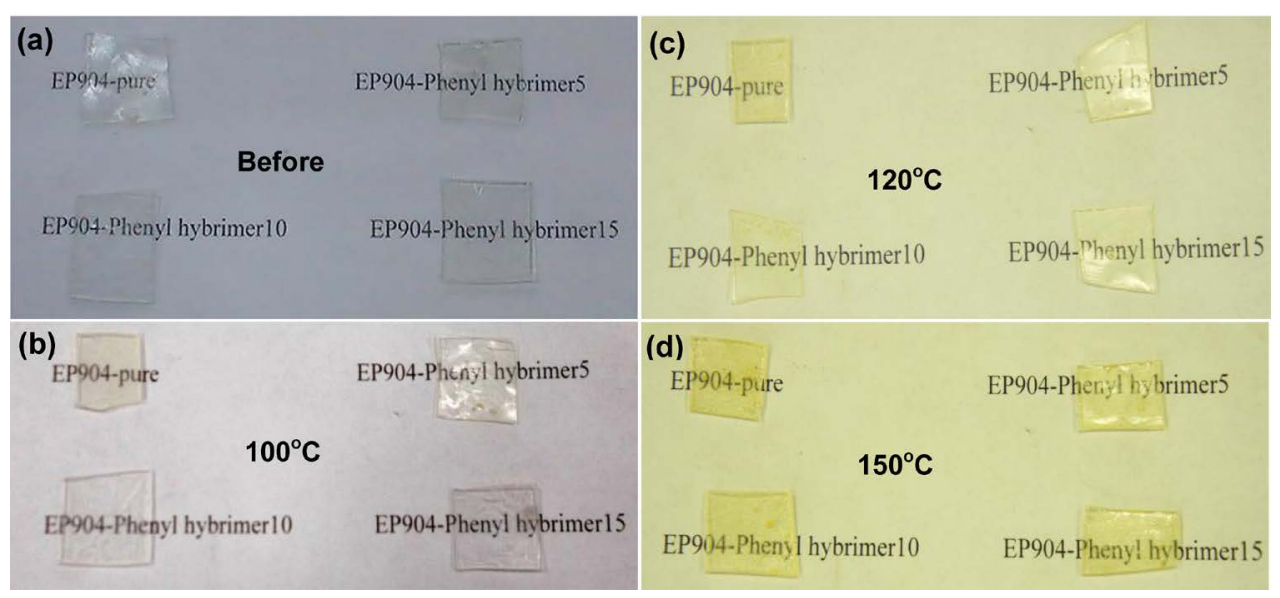

Figure 7. The photographs of epoxy and epoxy/siloxane hybrimer before/after thermal aging at 100/ $120 / 150^{\circ} \mathrm{C}$ for $24 \mathrm{~h}$.
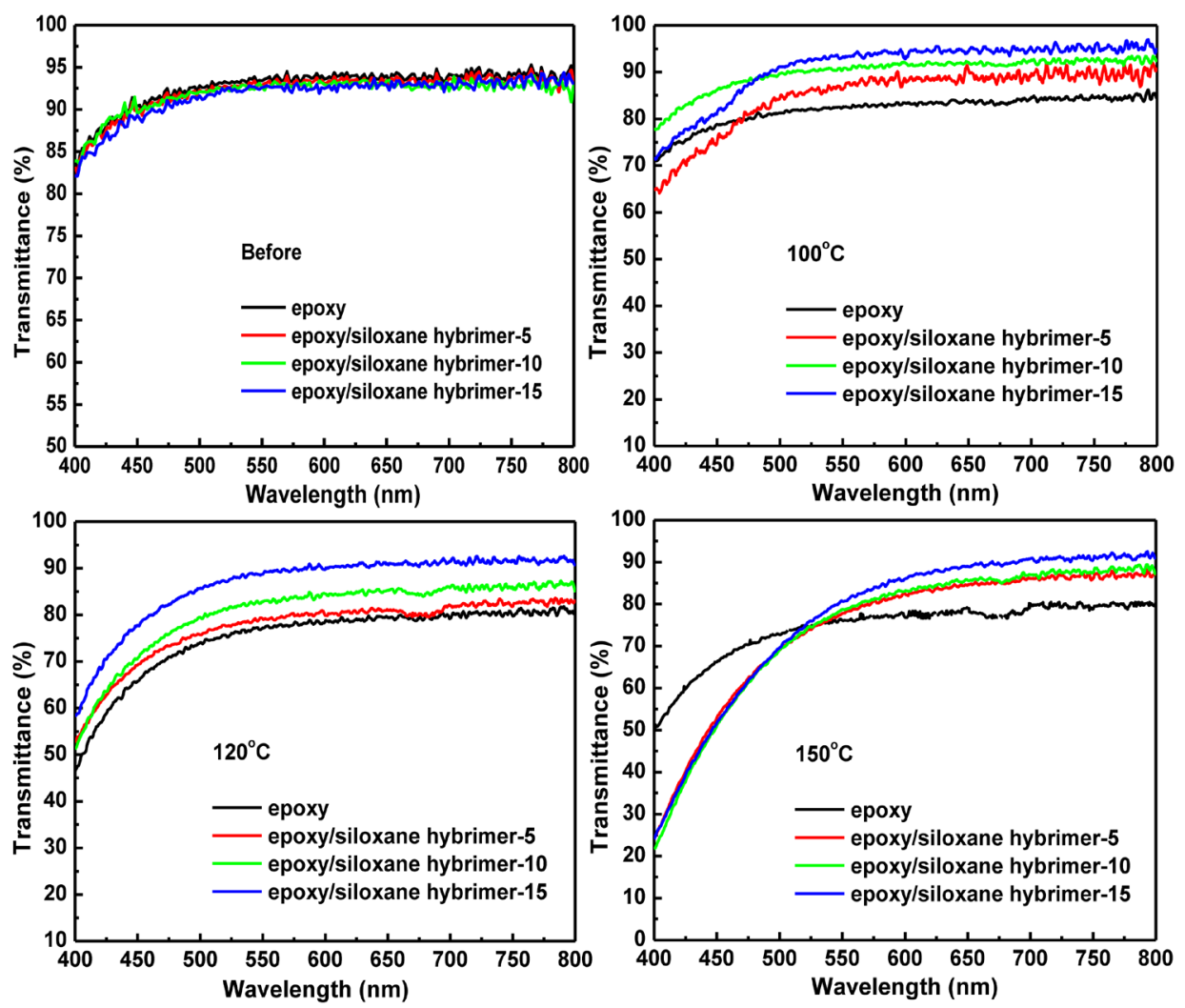

Figure 8. Transmittance spectra of the epoxy and epoxy/siloxane hybrimer before/after thermal aging at $100 / 120 / 150^{\circ} \mathrm{C}$ for $24 \mathrm{~h}$.

The refractive index (RI) of a LED encapsulant is an important factor related to the luminescence efficiency in white and high-power LEDs through enhanced light extraction efficiency. Therefore, the larger the RI of the encapsulating material, the higher the light extraction of the LED device [12]. Table 3 shows the RIs of the samples before and after thermal aging at $100 / 120 / 150^{\circ} \mathrm{C}$ in air for $1 / 3 / 7$ days. As shown in Table 3, the RIs of the hybrimers $(1.66$ - 1.70) were higher than that of epoxy (1.65) before thermal aging, and increased with increasing phenyl-siloxane, even though the thermal aging temperature and duration was $150^{\circ} \mathrm{C}$ and 7 days, respectively. The epoxy/siloxane hybrimers had high refractive indexex of over 1.62 without reference to the 

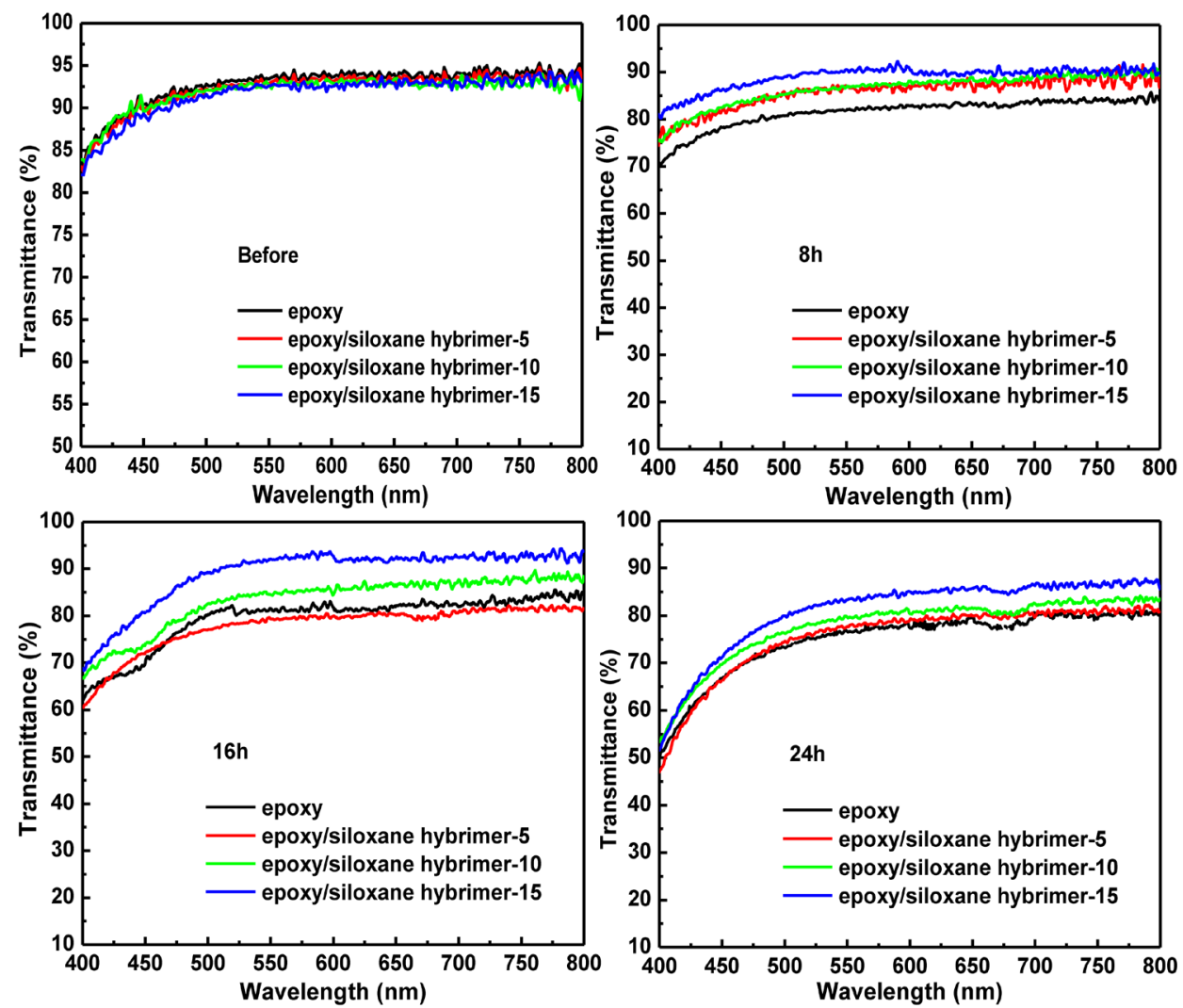

Figure 9. Transmittance spectra of the epoxy and epoxy/siloxane hybrimer before/after UV aging at $365 \mathrm{~nm}$ wavelength for $8 / 16 / 24 \mathrm{~h}$.

Table 1. The transmittance on 460 and $550 \mathrm{~nm}$ wavelength of hybrids before and after thermal aging.

\begin{tabular}{cccccccccc}
\hline Hybrids & \multicolumn{2}{c}{ Before } & \multicolumn{2}{c}{$100^{\circ} \mathrm{C}$} & \multicolumn{2}{c}{$120^{\circ} \mathrm{C}$} & \multicolumn{2}{c}{$150^{\circ} \mathrm{C}$} \\
\hline Transmittance (\%) & 460 & $550 \mathrm{~nm}$ & 460 & $550 \mathrm{~nm}$ & 460 & $550 \mathrm{~nm}$ & 460 & $550 \mathrm{~nm}$ \\
\hline Epoxy & 91 & 93 & 79 & 82 & 68 & 77 & 68 & 76 \\
Epoxy/siloxane hybrimer-5 & 91 & 93 & 78 & 87 & 71 & 79 & 57 & 78 \\
Epoxy/siloxane hybrimer-10 & 91 & 93 & 81 & 91 & 74 & 83 & 57 & 78 \\
Epoxy/siloxane hybrimer-15 & 90 & 92 & 85 & 94 & 80 & 89 & 57 & 81 \\
\hline
\end{tabular}

Table 2. The transmittance on 460 and $550 \mathrm{~nm}$ wavelength of hybrids before and after UV aging.

\begin{tabular}{|c|c|c|c|c|c|c|c|c|}
\hline \multirow{2}{*}{$\begin{array}{c}\text { Hybrids } \\
\text { Transmittance (\%) }\end{array}$} & \multicolumn{2}{|c|}{ Before } & \multicolumn{2}{|c|}{$8 \mathrm{~h}$} & \multicolumn{2}{|c|}{$16 \mathrm{~h}$} & \multicolumn{2}{|c|}{$24 \mathrm{~h}$} \\
\hline & 460 & $550 \mathrm{~nm}$ & 460 & $550 \mathrm{~nm}$ & 460 & $550 \mathrm{~nm}$ & 460 & $550 \mathrm{~nm}$ \\
\hline Epoxy & 91 & 93 & 79 & 82 & 73 & 81 & 69 & 77 \\
\hline Epoxy/siloxane hybrimer-5 & 91 & 93 & 82 & 87 & 73 & 79 & 69 & 78 \\
\hline Epoxy/siloxane hybrimer-10 & 91 & 93 & 83 & 87 & 77 & 85 & 72 & 80 \\
\hline Epoxy/siloxane hybrimer-15 & 90 & 92 & 87 & 90 & 83 & 92 & 74 & 84 \\
\hline
\end{tabular}

composition due to the presence of many phenyl groups. Furthermore, the RIs of the samples decreased incrementally with thermal aging temperature and duration. In general, phenyl-containing materials are susceptible to yellowing, because phenyl radicals are cleaved from backbone chains by thermal aging. The epoxy/siloxane 
Table 3. The refractive index of hybrids before and after thermal aging.

\begin{tabular}{|c|c|c|c|c|c|c|c|c|c|c|}
\hline Time (Days) & \multirow{2}{*}{ Before } & \multicolumn{3}{|c|}{1} & \multicolumn{3}{|c|}{3} & \multicolumn{3}{|c|}{7} \\
\hline Degree $\left({ }^{\circ} \mathrm{C}\right)$ & & 100 & 120 & 150 & 100 & 120 & 150 & 100 & 120 & 150 \\
\hline Epoxy & 1.65 & 1.59 & 1.55 & 1.48 & 1.50 & 1.45 & 1.39 & 1.36 & 1.32 & 1.28 \\
\hline Epoxy/siloxane hybrimer-5 & 1.66 & 1.61 & 1.56 & 1.49 & 1.54 & 1.48 & 1.40 & 1.38 & 1.35 & 1.29 \\
\hline Epoxy/siloxane hybrimer-10 & 1.68 & 1.64 & 1.60 & 1.54 & 1.55 & 1.49 & 1.43 & 1.40 & 1.36 & 1.31 \\
\hline Epoxy/siloxane hybrimer-15 & 1.70 & 1.65 & 1.64 & 1.58 & 1.56 & 1.50 & 1.44 & 1.41 & 1.37 & 1.32 \\
\hline
\end{tabular}

hybrimers showed substantial thermal stability against yellow discoloration and had high refractive indexes. This stability is due to strong siloxane network bonds and a branched structure formed by almost complete condensation of organosilane precursors. This dense and highly-condensed oligosiloxane network-based branch structure effectively prevents the generation of cleaved phenyl radicals.

\section{Conclusion}

Epoxy/siloxane hybrimers with different phenyl-siloxane concentrations (5 - 15 wt\%) were synthesized through sol-gel condensation and a polymerization reaction. The phenyl-siloxane was successfully incorporated into the epoxy resin system without phase separation. The cured epoxy/siloxane hybrimers were superior in terms of their thermal and optical properties as compared with epoxy resin. The epoxy/siloxane hybrimers had a high thermal stability, and their refractive indexes were higher than that of epoxy resin. Moreover, the epoxy/siloxane hybrimers showed almost no yellowing upon thermal aging at $120^{\circ} \mathrm{C}$ for $24 \mathrm{~h}$ under air. It was concluded that these hybrimers were excellent for the packaging of high-power white LEDs owing to their ability to maintain a great thermal and UV resistance, a high transmittance at 460/550 nm (91/93\%), and a high refractive index at a wavelength of $632.8 \mathrm{~nm}(1.66-1.70)$.

\section{Acknowledgements}

The authors thank the Chung Shan Institute of Science and Technology for supporting this work (CSIST-0497V211(101)).

\section{References}

[1] Mehr, M.Y., van Driel, W.D., Jansen, K.M., Deeben, P., Boutelje, M. and Zhang, G.Q. (2013) Photodegradation of Bisphenol A Polycarbonate under Blue Light Radiation and Its Effect on Optical Properties. Optical Materials, 35, 504-508. http://dx.doi.org/10.1016/j.optmat.2012.10.001

[2] Kim, S.M., Lee, K.C., Yu, Y.M., Baek, J.H. and Jung, G.Y. (2009) Wafer-Level Packaged Light-Emitting Diodes Using Photodielectric Resin. IEEE Electron Device Letters, 30, 638-641. http://dx.doi.org/10.1109/LED.2009.2019834

[3] Yang, S.C., Kim, J.S., Jin, J.H., Kwak, S.Y. and Bae, B.S. (2010) Thermal Resistance of Cycloaliphatic Epoxy Rybrimer Based on Sol-Gel Derived Oligosiloxane for LED Encapsulation. Journal of Applied Polymer Science, 117, 2140-2145. http://dx.doi.org/10.1002/app.31702

[4] Wang, H., Lee, K.S., Ryu, J.H., Hong, C.H. and Cho, Y.H. (2008) Active Packaging Method for Light-Emitting Diode Lamps with Photosensitive Epoxy Resins. IEEE Photonics Technology Letters, 20, 87-91. http://dx.doi.org/10.1109/LPT.2007.910760

[5] Kim, J.P., Jang, M.S., Kim, W.H., Joo, J.Y., Cho, J.H. and Kim, D.W. (2012) Improvement in the Color Uniformity of LED by Microspheres Generated from Phase Separation. Optical Materials, 34, 1614-1617. http://dx.doi.org/10.1016/j.optmat.2012.04.009

[6] Gao, N., Liu, W.Q., Yan, Z.L. and Wang, Z.F. (2013) Synthesis and Properties of Transparent Cycloaliphatic EpoxySilicone Resins for Opto-Electronic Devices Packaging. Optical Materials, 35, 567-575. http://dx.doi.org/10.1016/j.optmat.2012.10.023

[7] Tao, P., Viswanath, A., Schadler, L.S., Benicewicz, B.C. and Siegel, R.W. (2011) Preparation and Optical Properties of Indium Tin Oxide/Epoxy Nanocomposites with Polyglycidyl Methacrylate Grafted Nanoparticles. ACS Applied Materials \& Interfaces, 3, 3638-3645. http://dx.doi.org/10.1021/am200841n 
[8] Hsu, C.W., Ma, C.M., Tan, C.S., Li, H.T. and Huang, S.C. (2012) Effect of Thermal Aging on the Optical, Dynamic Mechanical, and Morphological Properties of Phenylmethylsiloxane-Modified Epoxy for Use as an LED Encapsulant. Materials Chemistry and Physics, 134, 789-796. http://dx.doi.org/10.1016/j.matchemphys.2012.03.070

[9] Huang, W., Zhang, Y., Yu, Y.Z. and Yuan, Y.X. (2007) Studies on UV-Stable Silicone-Epoxy Resins. Journal of Applied Polymer Science, 104, 3954-3959. http://dx.doi.org/10.1002/app.26188

[10] Vanlathem, E., Norris, A.W., Bahadur, M., DeGroot, J. and Yoshitake, M. (2006) Novel Silicone Materials for LED Packaging and Optoelectronics Devices. Proceedings of SPIE, 6192, 619202-619209.

[11] Morita, Y., Tajima, S., Suzuki, H. and Sugino, H. (2008) Cationic Copolymerization of Epoxy Siloxane Monomer with Liquid Poly-Butadiene and Its Light Emitting Diode Encapsulation. Journal of Applied Polymer Science, 109, 18081813. http://dx.doi.org/10.1002/app.28212

[12] Lin, Y.H., You, J.P., Lin, Y.C., Tran, N.T. and Shi, F.G. (2010) Development of High-Performance Optical Silicone for the Packaging of High-Power LEDs. IEEE Transactions on Components, Packaging, and Manufacturing Technology, 33, 761-766. http://dx.doi.org/10.1109/TCAPT.2010.2046488

[13] Choi, J.K., Lee, D.H., Rhee, S.K. and Jeong, H.D. (2010) Observation of Tunable Refractive Indices and Strong Intermolecular Interactions in Newly Synthesized Methylene-Biphenylene-Bridged Silsesquioxane Thin Films. Journal of Physical Chemistry C, 114, 14233-14239. http://dx.doi.org/10.1021/jp909287f

[14] Roy, P.K., Iqbal, N., Kumar, D. and Rajagopal, C. (2014) Polysiloxane-Based Core-Shell Microspheres for Toughening of Epoxy Resins. Journal of Polymer Research, 21, 348-357. http://dx.doi.org/10.1007/s10965-013-0348-5

[15] Yang, S.C., Kim, J.S., Jin, J.H., Kwak, S.Y. and Bae, B.S. (2011) Cycloaliphatic Epoxy Oligosiloxane-Derived Hybrid Materials for a High-Refractive Index LED Encapsulant. Journal of Applied Polymer Science, 122, 2478-2485. http://dx.doi.org/10.1002/app.34375

[16] Chiu, Y.C., Ma, C.C., Liu, F.Y., Chiang, C.L., Riang, L. and Yang, J.C. (2008) Effect of P/Si Polymeric Silsesquioxane and the Monomer Compound on Thermal Properties of Epoxy Nanocomposite. European Polymer Journal, 44, 1003-1011. http://dx.doi.org/10.1016/j.eurpolymj.2008.01.033

[17] Kim, J.S., Yang, S.C. and Bae, B.S. (2010) Thermally Stable Transparent Sol-Gel Based Siloxane Hybrid Material with High Refractive Index for Light Emitting Diode (LED) Encapsulation. Chemistry of Materials, 22, 3549-3555. http://dx.doi.org/10.1021/cm100903b

[18] Chiang, C.L., Chang, R.C. and Chiu, Y.C. (2007) Thermal Stability and Degradation Kinetics of Novel Organic/ Inorganic Epoxy Hybrid Containing Nitrogen/Silicon/Phosphorus by Sol-Gel Method. Thermochimica Acta, 453, 97104. http://dx.doi.org/10.1016/j.tca.2006.11.013 